\title{
MODELO PARA APOIO ÀS COMPRAS PÚBLICAS SUSTENTÁVEIS COM AUXÍLIO MULTICRITÉRIO
}

\author{
Fernando Cerutti Aguiar \\ Universidade Candido Mendes \\ Av. Anita Peçanha, 100 - Parque São Caetano, Campos dos Goytacazes/RJ \\ fernandocerutti@gmail.com \\ Milton Erthal Jr. \\ Universidade Candido Mendes \\ Av. Anita Peçanha, 100 - Parque São Caetano, Campos dos Goytacazes/RJ \\ miltonerthal@hotmail.com \\ Claudio Melo \\ Universidade Candido Mendes \\ Av. Anita Peçanha, 100 - Parque São Caetano, Campos dos Goytacazes/RJ \\ claudiomelo.edu@gmail.com \\ Henrique da Hora \\ Instituto Federal de Educação, Ciência e Tecnologia Fluminense \\ R. Cel. Walter Kramer, 357 - Parque Vera Cruz, Campos dos Goytacazes/RJ \\ henrique.dahora@iff.edu.br
}

\section{RESUMO}

As compras públicas são um importante vetor para o desenvolvimento sustentável em todo mundo. No Brasil, a escolha de critérios sustentáveis nas licitações é de inteira responsabilidade dos gestores públicos que devem optar por um determinado item em um grande universo de opções. Este artigo propõe um modelo baseado no método multicritério AHP (Analytic Hierarchy Process) para auxiliar os gestores públicos na escolha do item sustentável mais conveniente para Administração Pública utilizando-se dos critérios preço, qualidade, impacto ambiental e impacto social. A pesquisa baseou-se nos dois materiais sustentáveis mais adquiridos pelo Ministério da Educação (MEC), definindo-se qual a melhor opção de escolha para estes, propondo também, um modelo que poderá servir de orientação para decisão de compras sustentáveis. Os resultados indicaram que o modelo serviu de apoio para escolha do melhor detergente e papel A4 sustentável, e que pode servir como exemplo para aquisição de qualquer item sustentável, desde que respeitada as características únicas de cada item, podendo conter critérios específicos de avaliação.

Palavra-chave: Compras públicas sustentáveis; Apoio multicritério a decisão; AHP; Administração pública; Ministério da Educação.

\begin{abstract}
Public procurement is an important driver for sustainable development worldwide. In Brazil, the selection of sustainable criteria in tenders is of entire responsibility of public managers, who must choose a given item in a wide range of options. This article proposes a model based on the AHP (Analytic Hierarchy Process) multi-criteria method to assist public managers in choosing the most convenient sustainable item for Public Administration using


the price, quality, environmental impact, and social impact criteria. The research was based on the two most commonly acquired sustainable materials by the Ministry of Education (Ministério da Educação-MEC), defining the best option for them, and also proposing a model that could serve as guidance for the decision of green procurement. Findings revealed that the model supported the selection of the best biodegradable detergent and sustainable A4 paper and that it can serve as an example for the purchase of any sustainable item, as long as the specific characteristics of each item are met, with the possibility of containing specific evaluation criteria.

Keywords: Green public procurement; Multi-criteria decision aid; AHP; Public administration; Ministry of Education.

\section{Como Citar:}

AGUIAR, Fernando Cerutti et al. Modelo para apoio às compras públicas sustentáveis com auxílio multicritério. In: SIMPÓSIO DE PESQUISA OPERACIONAL E LOGÍSTICA DA MARINHA, 19., 2019, Rio de Janeiro, RJ. Anais [...]. Rio de Janeiro: Centro de Análises de Sistemas Navais, 2019.

\section{INTRODUÇÃO}

Nas últimas décadas, o poder de compra do Estado passou a ser analisado sob a ótica da sustentabilidade, uma vez que se assistiu a ampliação dos debates sobre a necessidade de busca de uma agenda de desenvolvimento pleno - contemplando elementos de dimensões, ambientais e sociais - sobrepondo o velho debate sobre a necessidade de se buscar apenas o crescimento econômico per se como elemento garantidor da qualidade de vida e da prosperidade das populações (VILLARROEL, 2014).

Segundo Jesus (2014) o poder de compra governamental, aliado aos novos padrões de aquisições mais responsáveis e transparentes, representa uma quebra de paradigma com a utilização dos contratos públicos na promoção do desenvolvimento econômico, social e ambiental. Esse novo contexto direciona o Estado para melhorar sua eficiência administrativa de acordo com o modelo de desenvolvimento sustentável.

As compras públicas representam uma das atividades governamentais mais significativas na composição do Produto Interno Bruto (PIB) mundial, atingindo em 2015 percentuais que variam de 15\%, no caso de países membros da Organização para Cooperação e Desenvolvimento Econômico (OCDE), a 30\% em países em desenvolvimento. No Brasil, os dados indicam que mais de $20 \%$ do orçamento é empregado em compras e contratações pelo setor público. Portanto, as compras públicas têm o potencial de promover mercados e sistemas produtivos em nível global a partir da formulação de suas demandas com potenciais impactos nas dimensões econômicas, sociais e ambientais, que são as bases para a promoção do desenvolvimento sustentável, que por sua vez fundamentam o conceito de compra pública sustentável (CALVACANTI et. al., 2017).

Os decretos federais 7.746 de 2012 e 9.178 de 2017, estabelecem os critérios e práticas a serem adotados nas contratações públicas sustentáveis e significam uma readequação da "proposta mais vantajosa para a administração", levando-se em conta não apenas o menor preço, mas baixo impacto sobre os recursos naturais, maior vida útil e menor custo de manutenção do bem, a origem sustentável dos bens, entre outros. A adoção destes mecanismos pelo governo brasileiro está em conformidade com o Conselho Internacional para Iniciativas Ambientais Locais (ICLEI, 2015) que propõe compras sustentáveis que assegurem produtos e serviços adquiridos pelas organizações alcancem uma boa relação qualidade-preço, 
considerando o ciclo de vida do produto, e gerem benefícios não somente para as organizações, para o meio ambiente, a sociedade e a economia. Comprar de maneira sustentável envolve um foco em longo prazo ao invés de uma visão de curto prazo.

De acordo com o "Painel de Compras Governamentais" do portal do Ministério do Planejamento (BRASIL, 2018), as compras de itens sustentáveis em relação ao total de materiais adquiridos pelo Governo Federal, evoluiu de 1,59\% em 2013 para 1,84\% em 2017. Esses dados demonstram que houve uma irrelevante evolução dos processos que incentivam a compra de itens sustentáveis. Além de aspectos legais, outros mecanismos devem ser avaliados para a promoção dessas boas práticas na administração pública, tais como: a educação ambiental, capacitação dos servidores, selos de certificações de conformidades, incentivos fiscais, entre outros.

Para o ICLEI (2015), muitos profissionais de compras ainda encontram dificuldade para definir o que é um produto ou serviço "sustentável”, "ambientalmente ou socialmente preferível”, e como incluir esta demanda no edital. Alencastro, Silva e Lopes (2014) destacam que as especificações dos produtos constantes no Catálogo de Materiais do Governo Federal (CATMAT) possuem um papel relevante para a implementação das licitações sustentáveis, principalmente enquanto ainda não existe um "selo verde". O uso das informações do CATMAT possibilita maior agilidade e segurança para os gestores identificarem adequadamente a especificação de produtos considerados sustentáveis no processo de compra. Segundo Calvacanti et. al. (2017), a forma como os itens sustentáveis são classificados precisa ser aprimorada, pois a classificação, atualmente, não é feita por um órgão ou instituição especializada, mas sim pelos próprios usuários do CATMAT.

Atualmente existem 1032 itens cadastrados como sustentáveis no catálogo de matérias do governo federal, no entanto somente para papel A4, existem 14 opções. Assim, se forem considerados vários critérios de escolha, além do preço de aquisição, como qualidade, impacto ambiental, custo de manutenção, descarte e outros, torna-se difícil para o servidor público optar pela melhor escolha de material entre as opções existentes no mercado.

Tomando como base de estudo os materiais sustentáveis mais adquiridos pelas Instituições Públicas Federais de Ensino, este artigo propõe um modelo de análise multicritério que visa auxiliar os gestores públicos para a elaboração de editais cujo objetivo é a aquisição de produtos ou serviços, atendendo aos requisitos legais (ex.: critério custo), além de atender os aspectos de qualidade, sustentabilidade ambiental e social.

O trabalho propõe um exemplo de como podem ser avaliados os itens sustentáveis e inseridos nas licitações públicas sem afetar a legalidade do processo, auxiliando e sustentando a decisão dos gestores públicos quanto a escolha de produtos ou serviços a serem adquiridos por órgãos públicos e que produzam efeitos socioambientais positivos no Brasil.

\section{REFERÊNCIAL TEÓRICO}

\subsection{Compras Públicas Para o Desenvolvimento Sustentável}

O tema de Compras Públicas Sustentáveis (CPS) vem ganhando, a cada dia, novos adeptos no cenário internacional, especialmente nos últimos 20 anos, em virtude do crescente aprofundamento das discussões sobre as formas de se atingir o desenvolvimento sustentável dos países, a partir da utilização de preceitos e ferramentas cuja origem data da década de 60, com o início do movimento ambientalista em nível global. (CALVACANTI et. al., 2017)

Segundo Souza e Olivero (2010), o poder de compra pode ser exercido pela empresa privada, órgão público, cooperativa, por qualquer organização ou indivíduo que ao adquirem produtos ou serviços estabelecem exigências necessidades ou padrões que podem torná-los indutores da qualidade, da produtividade, de inovações tecnológicas, contribuindo para a geração de emprego, ocupação, renda, competitividade e desenvolvimento do País. É nesse 
contexto que a escala das compras governamentais produz um efeito cascata sobre os fornecedores, multiplicando investimentos na direção da sustentabilidade, podendo transformar-se numa ferramenta importante de promoção do desenvolvimento sustentável na esfera pública, com repercussão direta na iniciativa privada.

Devido a esse notável poder de compra, e segundo a estratégia de liderar pelo exemplo, os governos em todo o mundo vêm utilizando as compras públicas como ferramentas para promover políticas públicas voltadas ao desenvolvimento sustentável. Desta forma, eles exercem um importante papel indutor não apenas ao criar regulações, impostos e incentivos, mas também ao serem os consumidores mais ativos do mercado (MOURA, 2013).

Como ferramentas voluntárias de adesão por parte do setor produtivo, as CPS podem ajudar os governos a atingirem, por exemplo, metas relacionadas às mudanças climáticas, à gestão de resíduos sólidos e à gestão de recursos hídricos. Podem ser adotados produtos que reduzam o impacto nas florestas por meio da compra de madeira certificada, da redução da geração de resíduos e, também, do desperdício no uso da água, entre outras medidas possíveis (MOURA, 2013).

Por fim, importante ressaltar a importância das CPS por meio de Lopes e Oliveira (2012) quando destacam que a escolha de critérios ambientais como requisito de um produto ou serviço diminui ou evita a ocorrência de impactos negativos durante o ciclo de vida do produto, aos quais estão associados custos ocultos, que, em vez de serem pagos pelo consumidor final, são absorvidos pelo governo/sociedade. Por exemplo: o uso de agrotóxicos na agricultura, os metais pesados nos componentes de eletroeletrônicos, os produtos químicos usados em detergentes, lâmpadas e medicamentos, causam poluição do ar, lençóis freáticos e solo.

\subsection{Método Analytic Hierarchy Process (AHP)}

A programação multicritério por meio do Analytic Hierarchy Process é uma técnica estruturada para tomada de decisão em ambientes complexos em que diversas variáveis ou critérios são considerados para a priorização e seleção de alternativas ou projetos. (VARGAS, 2010)

O método AHP (Analytic Hierarchy Process) foi desenvolvido por Tomas L. Saaty no início da década de 70 e é o método de multicritério mais amplamente utilizado e conhecido no apoio à tomada de decisão na resolução de conflitos negociados, em problemas com múltiplos critérios (MARINS; SOUZA; BARROS, 2009).

O AHP é uma das ferramentas de apoio à tomada de decisão multicritério com maior número de aplicações práticas reportadas na literatura, particularmente em problemas envolvendo avaliações subjetivas. As áreas de aplicação incluem engenharia, educação, indústria e setores governamentais; os problemas abordados são tipicamente de seleção e avaliação de alternativas, tornando-se adequado para uma ampla variedade de aplicações (TORTORELLA; FOGLIATTO, 2008).

Costa (2006) sintetiza as principais etapas do método AHP da seguinte forma: construção de hierarquia, identificando o foco principal, os critérios, subcritérios (quando houver) e alternativas; aquisição de dados ou coleta de julgamentos de valor emitidos por especialistas; síntese de dados obtidos dos julgamentos, calculando-se a prioridade de cada alternativa em relação ao foco principal; análise da consistência de julgamento, identificando o quanto o sistema de classificação utilizado consiste na classificação de alternativas viáveis.

\section{METODOLOGIA}

Com o objetivo de auxiliar os gestores públicos quanto a descrição do objeto sustentável a ser licitado, fundamentando a opção de compra, este artigo propõe um exemplo prático e amparado pela legislação atual de como os gestores públicos podem estimular as 
compras públicas sustentáveis e com auxílio do método de análise hierárquica (AHP), tomar decisões conscientes, baseadas não somente no critério custo, mas também nos socioambientais. O método AHP foi escolhido devido a facilidade de implementação, podendo ser empregado de forma disseminada na administração pública federal, além de permitir a quantificação de critérios subjetivos (BHUSHAN; RAI, 2004).

A pesquisa baseou-se nos itens sustentáveis mais adquiridos pelo Ministério da Educação, já que este é o Ministério com maior participação nas compras públicas sustentáveis brasileiras (BRASIL, 2018) e, portanto, tem potencial para incentivar o mercado de produtos e serviços que contemplem a sustentabilidade socioambiental.

As alternativas consideradas neste trabalho consistem em materiais de consumo utilizados em grande escala por Instituições de Ensino, como por exemplo: papel A4, canetas, material de limpeza, entre outros. O foco do modelo proposto consiste em apontar aspectos relevantes a serem descritos no edital de aquisição dos bens, que posteriormente serão objeto do pregão eletrônico. Uma importante contribuição desta modelagem é a proposta de uma estrutura de critérios que atendam aspectos socioambientais e não apenas a visão reducionista do aspecto econômico, exigido por lei. A partir da definição dos critérios, foram consultados especialistas (diretores da área de compra do IF Fluminense) para a ponderação dos pesos dos critérios. Os especialistas foram incentivados a responder um questionário, no formato do google formulários, o que permitiu definir a matriz dos pesos dos critérios. Para entender o desempenho das alternativas à luz de cada critério assumido no problema foram realizadas pesquisas de mercado e os dados obtidos foram expressos em uma tabela de pagamentos. Após a obtenção dos dados utilizou-se o software IPE 1.0 para realização dos cálculos pelo método AHP. Por fim, como resultado desta pesquisa, é proposto um modelo de avaliação que pode ser útil como apoio a decisões de compras para os demais itens sustentáveis adquiridos por Instituições de Ensino.

\subsection{MODELAGEM}

O MEC adquire anualmente uma ampla gama de produtos considerados sustentáveis, no entanto, parte significativa destes não apresenta, de forma clara os atributos de sustentabilidade socioambiental. Assim, inicialmente, analisou-se os dois itens mais adquiridos pelo MEC e que possuem opções sustentáveis bem definidas. A partir de então, foi realizada uma pesquisa para identificação e viabilidade de fornecimento destes itens no mercado nacional. Para facilitar a compreensão e dimensão do modelo proposto, um estudo de caso foi conduzido com os dois materiais adquiridos com maior frequência e que apresentam diferentes opções no mercado: detergente e papel A4. A aplicação prática deste estudo apresenta soluções específicas para os itens pesquisados, no entanto, o modelo pode (deve) ser alterado quanto aos critérios e sua ponderação de pesos, para atender as necessidades de compras de itens diversos na esfera pública ou privada.

\subsubsection{Alternatívas Sustentáveis}

Como primeira etapa do processo de escolha, parte-se da pesquisa das opções existentes no mercado para os produtos aos quais se pretende adquirir, definindo-se as alternativas sustentáveis. Para isto foram realizadas pesquisas em portais especializados, no Plano de Logística Sustentável do Ministério do Meio Ambiente (Brasil, 2013), que cita algumas opções para itens sustentáveis e no catálogo de materiais do governo federal (CATMAT, 2018).

Para o item detergente, observou-se que existem duas principais categorias consideradas sustentáveis: detergentes formulados com componentes químicos biodegradáveis e detergentes formulados 100\% com compostos orgânicos. Existem atualmente no mercado diversos produtos com variadas composições químicas que são consideradas biodegradáveis, sendo que, não cabe a este trabalho analisar a composição 
química de cada produto. No entanto, fica evidente a distinção entre estes dois grupos de material, pois aqueles que possuem $100 \%$ de compostos orgânicos tendem a possuir características consideravelmente diversas dos demais. Como exemplo para este estudo, utilizou-se o detergente tipo lava louças concentrado, com embalagem grande de 05 litros, de modo a maximizar ainda mais o potencial sustentável do produto.

Quanto ao papel, o PLS do Ministério do Meio Ambiente (Brasil, 2013) sugere duas opções sustentáveis. A primeira, papel confeccionado com madeira de origem legal, comprovado por meio de certificação e não clorado. A segunda opção é o papel reciclado, composto de no mínimo $25 \%$ de aparas pós-consumo (aquelas provenientes geralmente pelos catadores de papel) e o restante de aparas pré-consumo (provenientes das fábricas).

A vantagem do papel certificado não clorado é possuir comprovação de origem de madeira de reflorestamento e ainda eliminar o principal processo poluidor que é a utilização do cloro. No entanto, de acordo com Ferraz (2009) o papel reciclado tende a ser ecologicamente mais vantajoso pois este não necessita de novo plantio ou derrubada de árvores, portanto ele tem vantagens sobre o papel branco de origem certificada, que necessitará de novos plantios, por melhor que sejam as práticas em seu plantio e processamento.

Após pesquisa nos principais portais de fornecedores de papel A4 no mercado nacional, não foram encontrados papel do tipo não clorado, somente dos tipos com certificação ou reciclados, sendo assim, estas são as duas alternativas viáveis a serem adotadas pelas instituições públicas, portanto objeto deste estudo.

No quadro 1 apresenta-se a descrição completa das alternativas utilizadas para elaboração desta pesquisa.

Quadro 1 - Alternativas de materiais sustentáveis

\begin{tabular}{|c|c|}
\hline Material & Alternativas sustentáveis \\
\hline Detergente & $\begin{array}{l}\text { Alternativa 1: Detergente lava louças concentrado. Embalagem com } 05 \text { litros. } \\
\text { Formulado com tensoativo biodegradável. Rendimento mínimo } 100 \text { litros. } \\
\text { Alternativa 2: Detergente lava louças concentrado. Embalagem com } 05 \text { litros. } \\
\text { Formulado com base } 100 \% \text { vegetal e sem ativos petroquímicos. Rendimento } \\
\text { mínimo } 20 \text { litros }\end{array}$ \\
\hline Papel A4 & $\begin{array}{l}\text { Alternativa 1: Papel A4 confeccionado com madeira de origem legal. Dimensão: } \\
210 x 297 \mathrm{~mm} \text {. Gramatura } 75 \text {. Cor branca. Embalagem com } 500 \text { Folhas. } \\
\text { Alternativa 2: Papel A4 confeccionado com material reciclado composto de no } \\
\text { mínimo 25\% de aparas pós-consumo e o restante de aparas pré-consumo. } \\
\text { Dimensão: } 210 x 297 \text { mm. Gramatura } 75 \text {. Cor branca. Embalagem com } 500 \text { Folhas. }\end{array}$ \\
\hline
\end{tabular}

Fonte: Elaborado pelo autor

\subsubsection{Critérios}

A escolha dos critérios para aquisição de material sustentável foi pautada em aspectos legais, publicações científicas e princípios básicos referentes ao desenvolvimento sustentável. Santos (2016), defende que as compras públicas sustentáveis devem não só integrar critérios ambientais, sociais e econômicos, mas também considerar a importância da qualidade e durabilidade dos materiais a serem adquiridos, garantindo assim maior eficiência dos produtos que impactam também nas questões sustentáveis. Para alinhar o melhor custo benefício com aspectos ambientais e sociais, atendo às três dimensões do desenvolvimento sustentável, propõe-se que os principais critérios para todos os itens sejam: preço, qualidade; impacto ambiental e social. No entanto, cada item a ser adquirido, por possuir caraterísticas únicas, deve ser avaliado de forma singular, podendo assim, ser atribuído critérios específicos que orientem a avalição de cada produto. 


\subsubsection{Preço}

Para este critério foram levantados preços em portais de venda online e consultas ao portal de preços do governo federal. Foram efetuadas cotações de marcas diferentes aplicando-se uma média aritmética para obtenção dos valores. Ressalta-se que todas as alternativas adotadas já estão consolidadas no mercado nacional, facilitando assim a obtenção de preços.

\subsubsection{Qualidade}

Para mensuração deste critério cada item pode ser avaliado de diferentes formas. Para aquisição de detergente, utilizou-se como parâmetro o rendimento do produto por metro quadrado, sendo que estes são informados pelos próprios fabricantes. No caso do papel A4, a qualidade pode ser avaliada pela resistência, durabilidade ou até mesmo a quantidade de tinta necessária para impressão.

Para mensurar a qualidade do papel foi realizada uma pesquisa com funcionários que trabalham nas gráficas e setores de reprografia do IF Fluminense. Utilizou-se um questionário (Apêndice I) baseado na escala de Likert (1932) em que os entrevistaram avaliaram os principais aspectos da qualidade do papel reciclado e branco. O questionário buscou avaliar, junto aos funcionários, a qualidade do papel segundo aspectos de resistência, durabilidade, facilidade de visualização e rendimento de tinta de impressão. Para cada avaliação o respondente tinha 5 opções, além da possibilidade de não opinar, variando entre muito bom e muito ruim. Para facilitar a mensuração atribui-se notas de 1 a 5 para cada item: muito bom (nota $=5$ ), bom (nota $=4$ ), entre bom e ruim (nota=3), ruim (nota=2) e muito ruim (nota=1). $\mathrm{O}$ resultado final foi obtido pela soma das notas de cada uma das alternativas.

\subsubsection{Impacto Ambiental}

Mensurar de maneira precisa os impactos ambientais dos materiais analisados é tarefa complexa e necessitaria de estudos e pesquisas aprofundadas. Tendo em vista estas dificuldades e para facilitar a análise deste critério, tomou-se como referência alguns estudos realizados sobre os materiais abordados que indicam o nível do impacto ambiental. Para detergentes, utilizou-se como parâmetro o estudo de Felipe e Dias (2017). Este estudo apresenta os diversos impactos no meio ambiente causados pelos detergentes que utilizam na sua formação os surfactantes sintéticos (alternativa 01). Os surfactantes sintéticos apresentam como problema ambiental mais importante a formação de espuma sobre a superfície da água. Este problema diminui a penetração dos raios solares, o que gera redução da produção primária (fitoplâncton) e reduz o oxigênio dissolvido, provocando a morte de organismos aquáticos. Estes produtos utilizam ainda em sua formulação matérias primas não-renováveis derivados de petróleo, as quais não são utilizadas nos detergentes orgânicos (alternativa 02). Outra desvantagem da primeira alternativa trata-se do processo de eutrofização. O fosfato, presente no efluente desses detergentes, é utilizado como nutriente pela vegetação aquática superficial favorecendo o seu crescimento excessivo, o que leva a menores concentrações de oxigênio no meio aquático provocando a morte dos outros seres vivos.

Para papel A4 utilizou-se como parâmetro o estudo realizado por Kinsella (2012), que faz uma comparação da eficiência ambiental entre papel branco (alternativa 1) e reciclado (alternativa 2) levando em consideração todos os recursos utilizados para sua produção, como matéria prima, energia, água, emissão de gases de efeito estufa e descarte de resíduos sólidos. O estudo aponta que o papel que economiza mais recursos e que evita mais tóxicos e poluentes, é o papel com conteúdo reciclado. De acordo com Kinsella, a produção de polpa de papel reciclado gera uma economia energética de 33\% em relação a polpa de papel virgem e emite $37 \%$ a menos de gases de efeito estufa. Além disso, ainda segundo Kinsella, a produção de papel reciclado contribui para redução do descarte de papel em aterros, impedindo sua 
contribuição para a criação de metano, um gás de efeito estufa 25 vezes mais potente que o dióxido de carbono.

\subsubsection{Impacto Social}

Quanto ao critério social, este pode ser avaliado com base no potencial econômico que determinado segmento pode trazer para a população, especialmente para aqueles que possuem pouca assistência do Estado, baixo nível de escolaridade ou estão longe dos grandes centros. De modo a simplificar a análise, para avaliação do papel, comparou-se a quantidade de trabalhadores envolvidos na coleta e classificação de resíduos sólidos em relação a quantidade de trabalhadores envolvidos com a fabricação de papel e seus derivados. Para isso, foram analisados os dados do censo de 2010 (IBGE, 2010) que indicam que existem 390.963 trabalhadores classificados nas ocupações "coletores de lixo e material reciclável" e "classificadores de resíduos”. Em contrapartida, dados do Ministério do Trabalho (Brasil, 2018) indicam que em 2010 existiam 173.219 vínculos ativos na indústria de fabricação de papel e seus derivados. Estes dados revelam o grande potencial socioeconômico que a indústria da reciclagem pode promover ao país, tendo em vista que a quantidade de trabalhadores envolvidos com a coleta e classificação de resíduos sólidos supera consideravelmente aqueles que trabalham diretamente na indústria de papel. Para reforçar a importância social do papel reciclado, destaca-se a pesquisa de Dagnino e Johansen (2017), que aponta que os trabalhadores envolvidos com a coleta de material reciclável estão entre a população mais vulnerável da sociedade, com remuneração substancialmente inferior e uma taxa de analfabetismo de aproximadamente $20 \%$, em comparação com os $06 \%$ do total de trabalhadores brasileiros.

Para avaliação do critério social na escolha do detergente, observou-se que os selos que certificam e atestam os detergentes 100\% naturais (alternativa 2) também atestam a responsabilidade social das empresas, fato este que não ocorre com todas as empresas que fornecem a alternativa 1. Assim, considerou-se que as empresas fornecedoras de produtos ecológicos (alternativa 2) tendem a ter maior comprometimento com as questões sociais, assim como as ambientais.

\subsubsection{Estrutura hierárquica}

A estrutura hierárquica apresentada na Figura 1, ilustra as alternativas e critérios utilizados neste trabalho para escolha de opção sustentável mais vantajosa para as Instituições Públicas. Foram utilizados os critérios: preço, qualidade, impacto ambiental e impacto social. Como se trata de um modelo, as alternativas foram representadas com números.

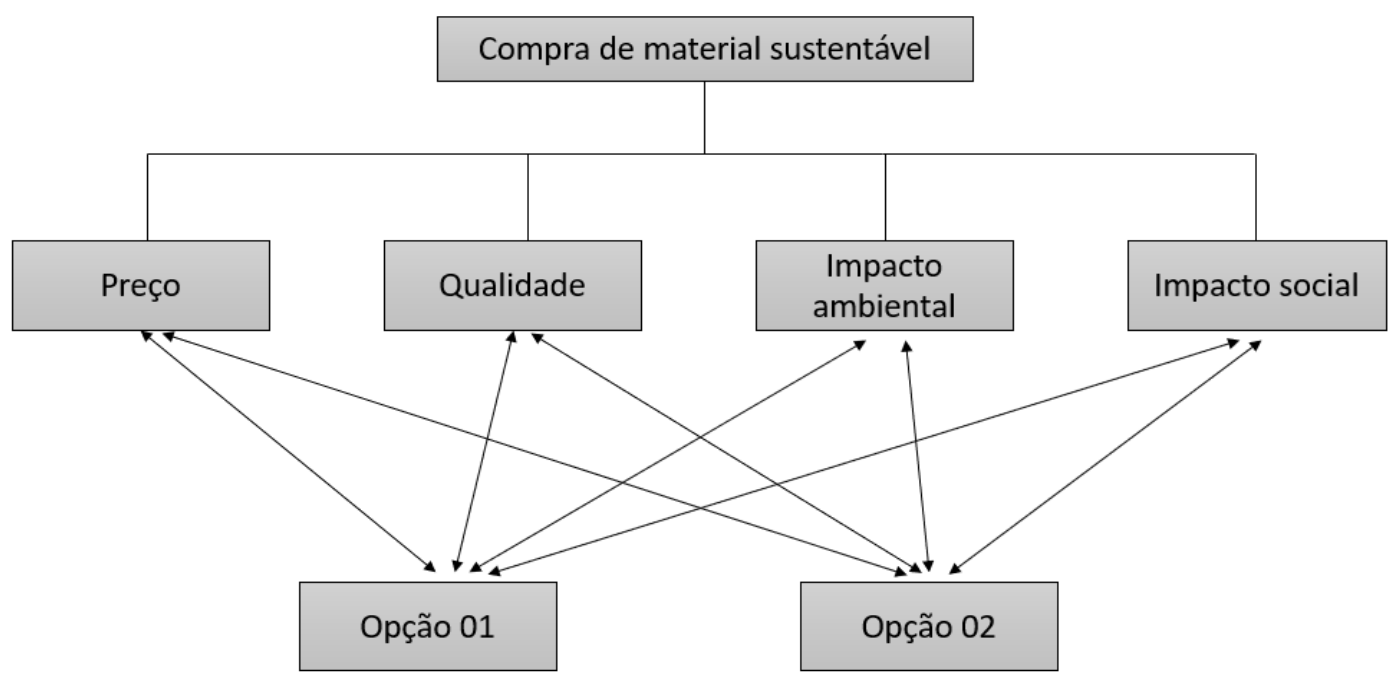

Figura 1 - Estrutura hierárquica do modelo proposto Fonte: Elaborado pelos autores 


\subsubsection{Definição de peso dos critérios}

Para ranqueamento em ordem de importância dos critérios estabelecidos, foi realizada uma pesquisa através de formulário enviado via email para os diretores administrativos dos diversos campi do Instituto Federal Fluminense. Estes gestores são responsáveis pela área de compras de cada uma das Unidades do Instituto, sendo assim, podem ser considerados como especialistas da área. O método Lawshe (1975) foi aplicado para mensuração dos pesos dos critérios. De acordo com Silva et. al. (2018), o método de Lawshe pode ser utilizado como uma ferramenta útil para finalidade de elicitação de critérios e pesos implementados aos modelos multicritérios de auxílio a decisão. Foram oferecidas as seguintes respostas aos especialistas para cada item (critério): (1) essencial; (2) importante, mas não essencial; (N) não sei/prefiro não opinar. A pesquisa foi realizada com 28 servidores no período de 03 a 07 de dezembro de 2018. Por meio da razão entre o número de respondentes que assinalaram a opção (1) "essencial” e o total de entrevistados (excluindo-se os que responderam "não sei/ prefiro não opinar”), foi obtida a frequência relativa (\%) de especialistas que consideraram o item como essencial (FRessencial). Posteriormente, foi calculado o valor de CVR (CVRcalculado) de cada item, conforme a seguinte fórmula:

$$
\mathrm{CVR}=\frac{\mathrm{n}_{\mathrm{e}}-\left(\frac{\mathrm{N}}{2}\right)}{\left(\frac{\mathrm{N}}{2}\right)}
$$

Onde: "ne" corresponde ao número de respondentes que assinalaram cada item como "essencial”, e "N" é o número total de respondentes, excluindo-se os que responderam "não sei/ prefiro não opinar".

Para cada "N" foi então anotado o valor de CVRcrítico, adotando-se os valores revisados e calculados pelo estudo de Wilson, Pan e Schumsky (2012), utilizando-se o nível de significância de 5\%. Por fim, os valores de CVRcalculado foram confrontados com o valor mínimo do CVR (CVRcrítico). Para que o item fosse mantido no questionário o valor de CVRcalculado deveria superar o valor de CVRcrítico, caso contrário o item seria excluído.

\section{RESULTADOS}

\subsection{APLICAÇÃo do MÉTODO LAWSHE PARA DEFINIÇÃo DE PESO DOS CRITÉRIOS}

Por meio da figura 2, apresenta-se o resultado da pesquisa realizada com os gestores da área de compras do IF Fluminense.

Foram obtidas 19 respostas por meio do formulário enviado para o email de 28 especialistas. Percebe-se que todos os critérios, com exceção do preço, foram marcados na maioria das respostas como "essencial”. Destaca-se que o critério preço registrou apenas sete respostas de critério "essencial” e ainda foi o único critério que apresentou duas respostas assinaladas como "não importante". Nenhum respondente assinalou "Não sei, prefiro não opinar”. O questionário ainda ofereceu a opção de sugerir algum critério que não estivesse na pesquisa, no entanto, nenhum respondente ofereceu sugestões. A partir destes dados infere-se que o questionário atingiu seu objetivo de validar os critérios para as CPS, pois estes foram avaliados, quase em sua totalidade, como essenciais ou importantes e nenhum outro critério foi sugerido. 


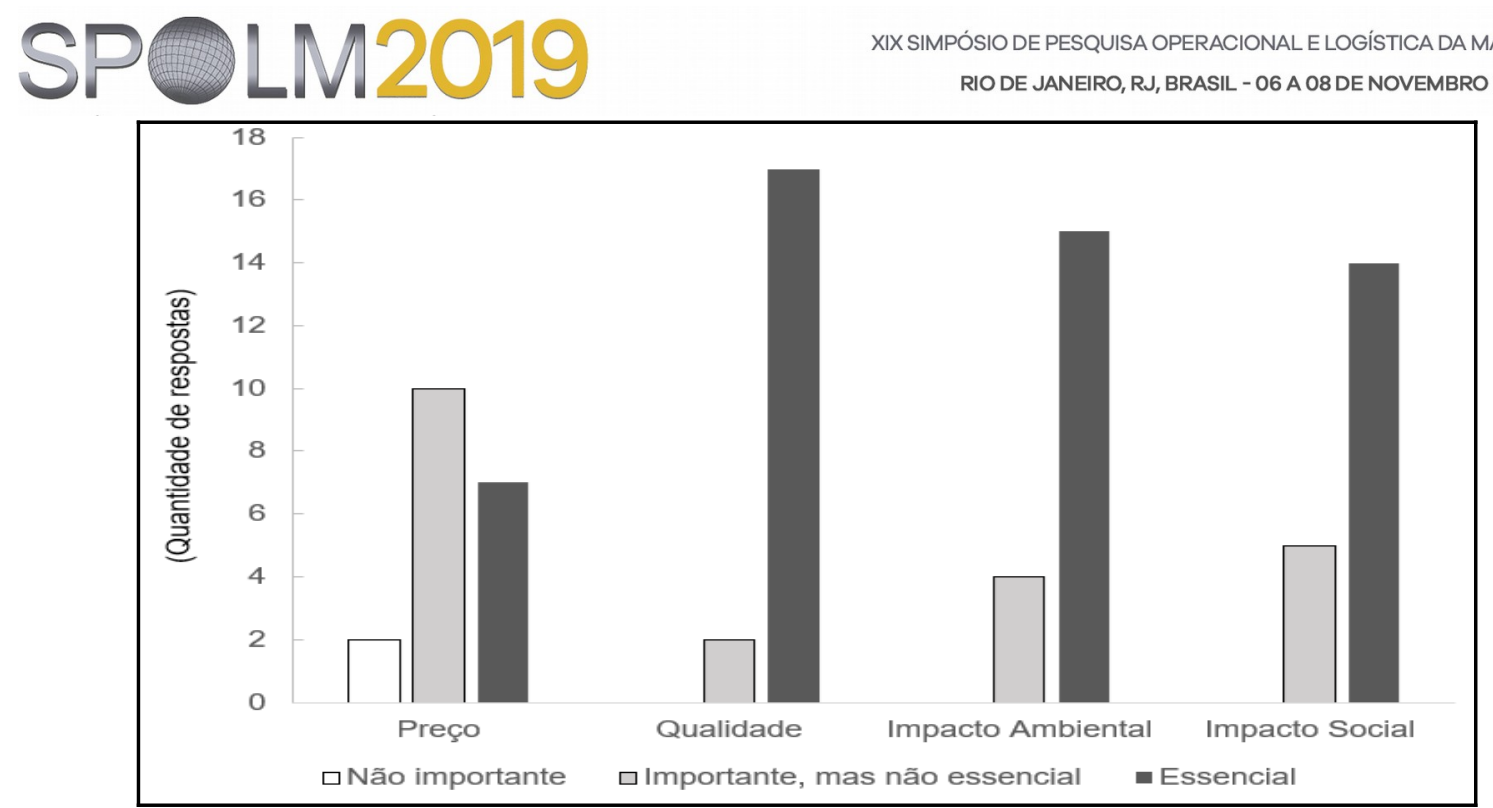

Figura 2 - Avaliação dos especialistas em relação aos critérios das CPS. Fonte: Elaborado pelos autores

Baseando-se no trabalho de Silva et. al. (2018), utilizou-se os valores do CVR calculado por meio do método Lawshe (tabela 1) para determinar o peso de cada critério. De acordo com os autores, a metodologia de Lawshe consegue mitigar a elicitação de preferências imprecisas ou não cooperativismo por parte dos decisores, pois a avaliação individual de cada critério por parte de múltiplos agentes, torna consensual a opinião subjetiva de cada decisor.

Tabela 1 - Resultado do método Lawshe para avaliação de critérios em CPS

\begin{tabular}{llccccccc}
\hline Cód. & Critério & ne & $\mathrm{N}$ & FRessencial & CVRcalc & CVRcrit & Decisão & Pesos \\
\hline C1 & Preço & 7 & 19 & $36,8 \%$ & $-0,263$ & 0,45 & Excluir & $-0,263$ \\
C2 & Qualidade & 17 & 19 & $89,5 \%$ & 0,789 & 0,45 & Manter & 0,789 \\
C3 & Impacto Ambiental & 15 & 19 & $78,9 \%$ & 0,579 & 0,45 & Manter & 0,579 \\
C4 & Impacto social & 14 & 19 & $73,7 \%$ & 0,474 & 0,45 & Manter & 0,474 \\
\hline \multicolumn{7}{c}{ Fonte: Adaptado de Neto et. al. (2015). } \\
\hline
\end{tabular}

Percebe-se na tabela 1 que de acordo com o método adotado, o critério preço deveria ser excluído da composição de critérios, no entanto, pelo fato de o preço ser fator indissociável das licitações públicas, além de que a maioria dos especialistas responderam que o critério é “importante, mas não essencial”, optou-se por mantê-lo na pesquisa, ainda que com peso significativamente inferior aos demais critérios.

\subsection{TABela de Pagamentos}

Apresenta-se na tabela 2 os valores obtidos por meio de pesquisas de mercado e os respectivos impactos sociais e ambientais de acordo com as alternativas e critérios apresentados.

Tabela 2 - Tabela de pagamentos com valores e estimativas obtidos a partir de pesquisas.

\begin{tabular}{ccccc}
\hline & \multicolumn{4}{c}{ Critérios } \\
\hline Alternativas & C1 - Preço & $\begin{array}{c}\text { C2 - Qualidade/ } \\
\text { Rendimento } \\
\text { Aquisição de detergente }\end{array}$ & $\begin{array}{c}\text { C3 - Impacto } \\
\text { Ambiental }\end{array}$ & $\begin{array}{c}\text { C4 - Impacto } \\
\text { Social }\end{array}$ \\
\hline A1 - Biodegradável & $\mathrm{R} \$ 56,00$ & 100 Litros & Médio & Baixo \\
A2 - 100\% Natural & $\mathrm{R} \$ 57,00$ & 20 Litros & Baixo & Médio
\end{tabular}




\begin{tabular}{|c|c|c|c|c|}
\hline \multirow[b]{3}{*}{ A1 - Certificado } & & \multicolumn{3}{|c|}{$\begin{array}{l}\text { XIX SIMPÓSIO DE PESQUISA OPERACIONAL E LOGÍSTICA DA MARINHA } \\
\text { RIO DE JANEIRO, RJ, BRASIL - O6 A O8 DE NOVEMBRO DE } 2019\end{array}$} \\
\hline & \multicolumn{4}{|c|}{ Aquisição de papel A4 } \\
\hline & $\mathrm{R} \$ 20,00$ & Figura 2 & Médio & Baixo \\
\hline A2 - Reciclado & $\mathrm{R} \$ 24,00$ & Figura 2 & Baixo & Médio \\
\hline
\end{tabular}

Fonte: Elaborado pelos autores

Para levantamento dos preços (C1), realizou-se uma média aritmética baseada em portais de venda destes produtos, assim como os valores referentes ao rendimento (C2) das alternativas de detergentes, que são fornecidos pelos fabricantes. Quanto a avalição do critério qualidade para as alternativas de papel, o gráfico representado pela figura 3, realizado por meio de pesquisa com funcionários que atuam na área de reprografia do IFFluminense, revelou uma grande vantagem para o papel branco em todos os quesitos avaliados. Por fim, quanto aos critérios C3 e C4, estes por serem de difícil mensuração foram avaliados em alto, médio ou baixo impacto conforme apontamentos realizados previamente no item 3.1.2 deste trabalho.

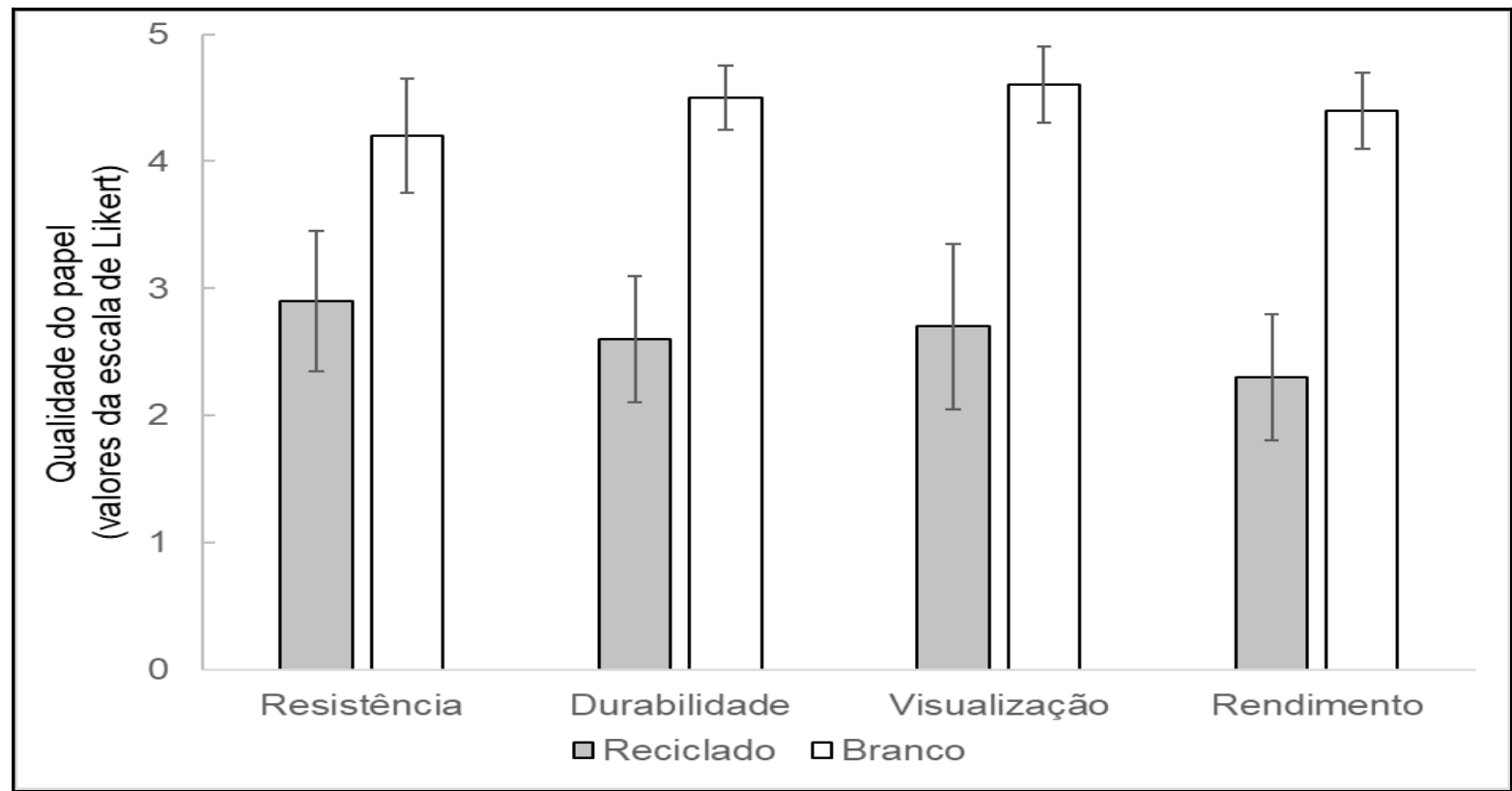

Figura 3 - Pesquisa de qualidade papel branco certificado x reciclado. Fonte: Elaborado pelos autores

\subsection{MATRIZ DE PESOS}

A partir da pesquisa com os especialistas foi elaborada a matriz de peso dos critérios, representada na figura 4, conforme a escala fundamental de Saaty (1990), que atribui valores de 1 a 9 visando a padronização de julgamentos dos avaliadores. Os valores dos pesos apurados na tabela 1 , foram associados a essa escala, atribuindo-se valores de 1 a 9 conforme a preferência de critérios, sendo 1 quando não existe e 9 quando existe preferência absoluta de um em relação ao outro.

\begin{tabular}{c|cccc|} 
Critérios & C1 & C2 & C3 & C4 \\
C1 & 1 & $1 / 8$ & $1 / 6$ & $1 / 5$ \\
C2 & 8 & 1 & 2 & 3 \\
C3 & 6 & $1 / 2$ & 1 & 2
\end{tabular}


Figura 4 - Representação da matriz de pesos elaborada a partir de pesquisa com os especialistas. Fonte:

Elaborado pelos autores

Para verificar a coerência dos valores de julgamento atribuídos pelos avaliadores, calculou-se a razão de consistência por meio do software IPÊ 1.0. O valor de 0,021 obtido por meio do software confirmou a coerência do julgamento, tendo em vista que este não pode ser superior a 0,1 , conforme Saaty.

\subsection{MATRIZ DEJUlgamento DE CRITÉRIOS}

O quadro 2, elaborado com base nos valores obtidos na tabela 2 (tabela de pagamentos) representa o julgamento dos critérios. Do mesmo modo que na elaboração da figura 4, utilizase a escala de Saaty (1990) para registro e ponderação dos valores.

Quadro 2 - Julgamento de critérios elaborada a partir da tabela de pagamentos.

\begin{tabular}{|c|c|c|c|c|c|}
\hline \multicolumn{6}{|c|}{ DETERGENTE } \\
\hline \multicolumn{3}{|c|}{ C1- Preço } & \multicolumn{3}{|c|}{ C2 - Qualidade/ Rendimento } \\
\hline \multirow{3}{*}{$\begin{array}{l}\text { A1 - Biodegradável } \\
\text { A2 - 100\% Natural }\end{array}$} & A1 & A2 & \multirow{3}{*}{$\begin{array}{l}\text { A1 - Biodegradável } \\
\text { A2 - 100\% Natural }\end{array}$} & A1 & A2 \\
\hline & 1 & 2 & & 1 & 5 \\
\hline & $1 / 2$ & 1 & & $1 / 5$ & 1 \\
\hline \multicolumn{3}{|c|}{ C3 - Impacto Ambiental } & \multicolumn{3}{|c|}{ C4 - Impacto Social } \\
\hline \multirow{3}{*}{$\begin{array}{l}\text { A1 - Biodegradável } \\
\text { A2 - 100\% Natural }\end{array}$} & A1 & A2 & \multirow{3}{*}{$\begin{array}{l}\text { A1 - Biodegradável } \\
\text { A2 - 100\% Natural }\end{array}$} & A1 & A2 \\
\hline & 1 & $1 / 4$ & & 1 & $1 / 4$ \\
\hline & 4 & 1 & & 4 & 1 \\
\hline \multicolumn{6}{|c|}{ PAPEL A4 } \\
\hline \multicolumn{3}{|c|}{ C1- Preço } & \multicolumn{3}{|c|}{ C2 - Qualidade/ Rendimento } \\
\hline \multirow{3}{*}{$\begin{array}{c}\text { A1 - Certificado } \\
\text { A2 - Reciclado } \\
\end{array}$} & A1 & A2 & \multirow{3}{*}{$\begin{array}{c}\text { A1 - Certificado } \\
\text { A2 - Reciclado }\end{array}$} & A1 & A2 \\
\hline & 1 & 2 & & 1 & 6 \\
\hline & $1 / 2$ & 1 & & $1 / 6$ & 1 \\
\hline \multicolumn{3}{|c|}{ C3 - Impacto Ambiental } & \multicolumn{3}{|c|}{ C4 - Impacto Social } \\
\hline \multirow{3}{*}{$\begin{array}{c}\text { A1 - Certificado } \\
\text { A2 - Reciclado } \\
\end{array}$} & A1 & A2 & \multirow{3}{*}{$\begin{array}{c}\text { A1 - Certificado } \\
\text { A2 - Reciclado } \\
\end{array}$} & $\mathbf{A 1}$ & A2 \\
\hline & 1 & $1 / 4$ & & 1 & $1 / 4$ \\
\hline & 4 & 1 & & 4 & 1 \\
\hline
\end{tabular}

Fonte: Elaborado pelos autores

Por fim, após a inserção de todos os dados no software IPÊ 1.0, obteve-se como resultado prioridade para a aquisição de detergente biodegradável e papel certificado (quadro 3), demonstrando que estas são as opções de aquisição mais vantajosas segundo os critérios e especialistas utilizados na pesquisa.

Quadro 3 - Resultado final do julgamento das alternativas

\begin{tabular}{|c|c|c|}
\hline Material & Alternativas sustentáveis & Julgamento \\
\hline \multirow[t]{2}{*}{ Detergente } & $\begin{array}{l}\text { Alternativa 1: Detergente lava louças concentrado. Embalagem } \\
\text { com } 05 \text { litros. Formulado com tensoativo biodegradável. } \\
\text { Rendimento mínimo } 100 \text { litros. }\end{array}$ & $52,95 \%$ \\
\hline & $\begin{array}{l}\text { Alternativa 2: Detergente lava louças concentrado. Embalagem } \\
\text { com 05 litros. Formulado com base } 100 \% \text { vegetal e sem ativos } \\
\text { petroquímicos. Rendimento mínimo } 20 \text { litros }\end{array}$ & $47,05 \%$ \\
\hline \multirow[b]{2}{*}{ Papel A4 } & $\begin{array}{l}\text { Alternativa 1: Papel A4 confeccionado com madeira de origem } \\
\text { legal. Dimensão: 210x297 mm. Gramatura } 75 \text {. Cor branca. } \\
\text { Embalagem com 500 Folhas. }\end{array}$ & $54,11 \%$ \\
\hline & $\begin{array}{l}\text { Alternativa 2: Papel A4 confeccionado com material reciclado } \\
\text { composto de no mínimo } 25 \% \text { de aparas pós-consumo e o restante de } \\
\text { aparas pré-consumo. Dimensão: } 210 \times 297 \mathrm{~mm} \text {. Gramatura } 75 \text {. Cor }\end{array}$ & $45,89 \%$ \\
\hline
\end{tabular}




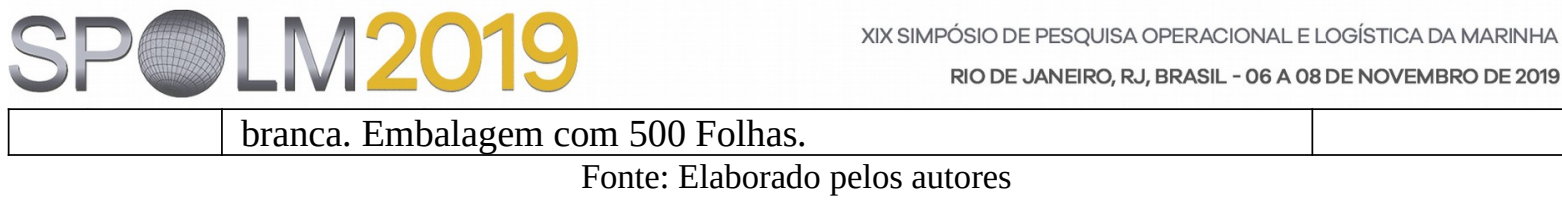

\section{DISCUSSÃO}

Este trabalho objetivou a proposição de um modelo de avaliação de materiais sustentáveis para definição de prioridades de aquisição para Instituições Públicas de Ensino. Sua contribuição se dá principalmente em relação a proposição metodológica, tendo em vista as inúmeras variáveis a serem consideradas em cada processo de compra, as quais devem ser consideradas individualmente por cada Instituição. O modelo diverge da proposta de Menezes, Silva e Linhares (2007) cujo objetivo é a proposição de uma nova metodologia de seleção de fornecedores que não seja baseada apenas no preço. O que se propõe aqui é uma metodologia para seleção dos materiais a serem objeto da licitação, os quais deverão ser precisamente descritos para garantir o sucesso da aquisição. A proposta é fundamentada em bases legais, e não necessita de nenhum ajuste ou entendimento diverso da legislação.

Os guias de licitações sustentáveis da Advocacia Geral da União (2016) e da Justiça do Trabalho (2014) trazem direcionamentos quanto as especificações e proposições de licitações sustentáveis, enquanto o manual Procura+ do ICLEI (2015), contempla de forma ampla o planejamento das contratações e traça um panorama dos critérios de licitações sustentáveis para alguns segmentos como construção civil, telecomunicações, limpeza e outros. Este trabalho, no entanto, delimita-se a demonstrar e propor um método prático para escolha de um objeto que atenta ao mesmo tempo os critérios sustentáveis e econômicos das Instituições Públicas.

Os resultados indicaram que o modelo pode auxiliar os gestores públicos de forma simples a selecionar os materiais mais vantajosos para serem objetos de futuras licitações.

Para que isso seja possível é preciso que as organizações se atentem as particularidades do objeto a ser adquirido e aos objetivos institucionais. No modelo proposto por exemplo, o papel branco foi escolhido como o mais adequado para a Instituição analisada de acordo com a ponderação de pesos de critérios dos especialistas questionados, que avaliaram o critério qualidade como o mais importante, no entanto, para outras instituições, que priorizem a sustentabilidade em detrimento da qualidade, o papel mais adequado poderá ser o reciclado. Assim, cada organização deverá fazer sua própria analise de acordo com seus próprios interesses e objetivos institucionais.

Outra questão importante a ser destacada é que os critérios de avaliação utilizados foram adequados para os materiais avaliados neste trabalho, no entanto, outros materiais podem ser avaliados sob critérios diferentes ou acrescentados novos critérios ou subcritérios. Por exemplo, para aquisição de aparelhos de ar condicionado, talvez o critério impacto social não seja de grande relevância, ele poderá ser substituído por exemplo por "eficiência energética”, ou acrescentado este critério como sendo um subcritério de qualidade.

A avaliação dos critérios impacto ambiental e social pelo fato de serem de grande subjetividade é um dos pontos de maior dificuldade de mensuração. A diversidade de opiniões a respeito do tema torna difícil precisar de forma objetiva e quantitativa a ponderação destes critérios. Neste cenário, é preciso que as Instituições interessadas aprofundem as pesquisas para cada material a ser avaliado, caso contrário, uma análise superficial, baseando-se na opinião de apenas um autor poderá levar a equívocos de avaliação e comprometer a correta decisão de compra. Nestes critérios, devido à dificuldade obtenção de valores, os critérios foram mensurados como "alto", "médio" ou "baixo".

O método de Lawshe (1975) apresentou-se adequadamente para obtenção do resultado pretendido, revelando e ponderando os critérios mais importantes de acordo com o questionário respondido pelos especialistas. Cabe aqui ressaltar que apesar da indicação para exclusão do critério "preço", optou-se por mantê-lo, mesmo que com ponderação bem abaixo 
dos demais, pois entende-se que apesar de não ser um critério muito importante segundo a opinião dos especialistas entrevistados, não pode ser desconsiderado do planejamento de compras, tendo em vista que as instituições públicas ou privadas possuem limitações orçamentárias e a depender do valor de um determinado material, mesmo que este seja de excelente qualidade e altamente sustentável, não poderá ser objeto licitação devido as limitações financeiras das organizações.

\section{CONSIDERAÇÕES FINAIS}

Com o objetivo de auxiliar os gestores públicos quanto as melhores opções de compra para matérias sustentáveis, este artigo identificou a melhor alternativa para aquisição de papel A4 e detergente de acordo a opinião de gestores que atuam em uma Instituição Pública de Ensino. O modelo propôs também que os principais critérios a serem avaliados nas CPS são: preço, qualidade, impacto ambiental e impacto social. No entanto, trata-se de um modelo norteador e demonstrativo, alertando-se que cada item a ser avaliado possui características próprias e que devem ser avaliadas individualmente, podendo ser criados critérios específicos para sua análise.

Foi possível identificar que os gestores consultados consideraram como principal critério em nível de importância a qualidade dos materiais, seguido pelo impacto ambiental, impacto social e por último o critério preço, sendo este, o único que recebeu registros de critério "não importante".

A grande subjetividade dos critérios Impacto Ambiental e Social são fatores que dificultaram a mensuração do resultado, e podem sofrer grande influência do avaliador, por isso, devem ser amplamente discutidos e estudados, de preferência por especialistas das áreas. O método AHP demonstrou ser a ferramenta apropriada para o estudo, tendo em vista a possibilidade de abranger tanto os critérios objetivos como os subjetivos, ser de fácil aplicabilidade e apontar em uma única direção.

Propõe-se para trabalhos futuros, a avaliação de outros materiais ou serviços comuns em licitações públicas e que estes sejam avaliados também em comparação com itens não sustentáveis de acordo com a especificidade de cada objeto a ser contratado.

\section{REFERÊNCIAS}

[1] ALENCASTRO, M. A. C.; SILVA, E. V.; LOPES, A. M. D. Contratações sustentáveis na administração pública brasileira: a experiência do Poder Executivo Federal. Revista de Administração Pública, v. 48, n. 1, p. 207-235, fev. 2014.

[2] BHUSHAN, N.; RAI, K. Strategic Decision Making: Applying the Analytic Hierarchy Process. New York: Springer. 2004.

[3] BRASIL. Advocacia-Geral da União. Consultoria-Geral da União. Guia Nacional de Licitações Sustentáveis. Brasília: AGU, 2016. . Conselho Superior da Justiça do Trabalho. Guia de Contratações

Sustentáveis da Justiça do Trabalho. Conselho Superior da Justiça do Trabalho. 2. ed., revisada, atualizada e ampliada, Brasília, 2014.

Decreto 7746 de 05 de junho de 2012. Regulamenta o art. $3^{\circ}$ da Lei $n^{\circ}$ 8.666, de 21 de junho de 1993, para estabelecer critérios e práticas para a promoção do desenvolvimento nacional sustentável e institui a Comissão Interministerial de Sustentabilidade na Administração Pública CISAP. Brasília, DF: Senado Federal. 2012. 
estabelecer critérios, práticas e diretrizes para a promoção do desenvolvimento nacional sustentável e institui a Comissão Interministerial de Sustentabilidade na Administração Pública CISAP. Brasília, DF: Senado Federal. 2017.

[7] MINISTÉRIO DO MEIO AMBIENTE. Plano de Logística Sustentável do Ministério do Meio Ambiente e do Serviço Florestal Brasileiro (PLS-MMA). 2013. Disponível em: http://www.mma.gov.br/images/arquivo/80063/PLS\%20MMA\%20\%20Versao\%20Final\%2021-05-13.pdf. Acesso em: 13 jun. 2018.

[8] _.MINISTÉRIO DO PLANEJAMENTO, DESENVOLVIMENTO E GESTÃO. Sistema de catalogação de material do governo federal (CATMAT). 2018.

Disponível em:

http://comprasnet.gov.br/acesso.asp?url=/Livre/Catmat/Conitemmat1.asp. Acesso em: 13 jun. 2018.

Painel de Compras. 2018. Disponível em: http://paineldecompras.planejamento.gov.br/ QvAJAXZfc/opendoc.htm?document=PaineldeCompras.qvw\&host=QVS@17-0112-bias04\&anonymous=true. Acesso: 20 mar. 2018.

[10] MINISTÉRIO DO TRABALHO. Bases Estatísticas RAIS e CAGED. 2018. Disponível em: http://bi.mte.gov.br/scripts10/dardoweb.cgi. Acesso em: 21 out. 2018.

[11] CALVACANTI, D.; OLIVEIRA, G.; AVIGNON, A.; SCHNEIDER, H.; TABOULCHANAS, K. Compras públicas sustentáveis: diagnóstico, análise comparada e recomendações para o aperfeiçoamento do modelo brasileiro. Comissão Econômica para a América Latina e o Caribe, Ministério do Meio Ambiente, 2017. Disponível em: https://repositorio.cepal.org/handle/11362/41009. Acesso em: 31 mar. 2018.

[12] COSTA, H. G. Auxilio Multicritério a Decisão: método AHP. Rio de Janeiro: ABEPRO, 2006.

[13] DAGNINO, R. S.; JOHANSEN, I. C. Os catadores no brasil: características demográficas e socioeconômicas dos coletores de material reciclável, classificadores de resíduos e varredores a partir do censo demográfico de 2010. Instituto de Pesquisa Econômica Aplicada, 2017. Disponível em: http://repositorio.ipea.gov.br/handle/11058/7796. Acesso em: 13 jun. 2018.

[14] FELIPE, L. O.; DIAS, S. C. Surfactantes sintéticos e biossurfactantes : vantagens e desvantagens. Química Nova na Escola, v. 39, n. 3, p. 228-236, 2017.

[15] FERRAZ, J. M. G. O papel nosso de cada dia. Artigos Técnicos-Científicos Embrapa, Jaguariúna, 2009.

[16] ICLEI. Manual Procura+ Um Guia para Implementação de Compras Públicas Sustentáveis. 3. ed. São Paulo: ICLEI, 2015.

[17] INSTITUTO BRASILEIRO DE GEOGRAFIA E ESTATÍSTICA. Censo demográfico 2010. Disponível em: https://sidra.ibge.gov.br/tabela/3592\#resultado. Acesso em: 13 jun. 2018.

[18] JESUS, C. S. Compras sustentáveis nas universidades federais: aspectos e propostas a partir do caso itaipu binacional. Rio de Janeiro: Centro Federal de Educação

Tecnológica Celso Suckow da Fonseca, 2014.

[19] KINSELLA, S. Paperwork: Comparing Recycled to Virgin Paper. Conservatree, 2012. 
Disponível em: http://conservatree.org/learn/WhitePaper\%20Why\%20Recycled.pdf. Acesso em: 21 jan. 2019.

[20] LAWSHE, C. H. A quantitative approach to content validity. Personnel Psychology, v. 28, p. 563-75, 1975.

[21] LIKERT, R. A Technique for the Measurement of Attitudes. Archives of psychology, v. 22, p. 5-55. New York University. New York, 1932.

[22] LOPES, M. N.; OLIVEIRA, V. C. F. Compras públicas sustentáveis. In: CONSAD DE GESTÃO PÚBLICA, 5., Brasília, 2012.

[23] MARINS, C. S.; SOUZA, D. O.; BARROS. M. S. O uso do método de análise hierárquica (AHP) na tomada de decisões gerenciais - um estudo de caso. In: SBPO 2009 - PESQUISA OPERACIONAL NA GESTÃO DO CONHECIMENTO, 41., 2009, Porto Seguro.

[24] MENEZES, R. A.; SILVA, R, B.; LINHARES, A. Leilões eletrônicos reversos multiatributo: uma abordagem de decisão multicritério aplicada às compras públicas brasileiras. Revista de Administração Contemporânea, v. 11, n. 3, p. 11-33, 2007.

[25] MOURA, A. M. As Compras públicas sustentáveis e sua evolução no Brasil. Boletim regional, urbano e ambiental, n. 7, jan./jun. 2013.

[26] NETO, A. R. S.; SHIMODA, E.; MARTINS, S. N.; \& JUNIOR, M. E. Seleção de critérios para priorização da manutenção preventiva de telecomunicações em plataformas de petróleo. Exatas \& engenharia, v. 5, n. 12, 2015.

[27] SAATY, T. L. How to make a decision: The analytic hierarchy process. European Journal of Operational Research, v. 48, n. 1, p. 9-26 , set. 1990.

[28] SANTOS, C. D. Critérios de sustentabilidade socioambiental nas compras públicas: um estudo na Universidade Federal do Tocantins. Palmas: Fundação Universidade Federal do Tocantins, 2016.

[29] SILVA, F. F.; RAMOS, J. C. N.; ERTHAL JÚNIOR, M.; SHIMOYA, A.; SOUZA, C. L. M. Seleção e ponderação de pesos de critérios: uma aplicação do método lawshe para problemas. In: SIMPÓSIO DE ENGENHARIA DE PRODUÇÃO UNIVERSIDADE FEDERAL DE GOIÁS , Catalão, Goiás, 2018.

[30] SOUZA, M. T. S.; OLIVERO, S. M. Compras Públicas Sustentáveis: um estudo da Incorporação de Critérios Socioambientais nas Licitações do Governo do Estado de São Paulo. In: ENCONTRO DA ANPAD, 34., 2010, Rio de Janeiro.

[31] TORTORELLA, G. L.; FOGLIATTO, F. S. Planejamento sistemático de layout com apoio de análise de decisão multicritério. Produção, v. 18, n. 3, p. 609-624, 2008

[32] VARGAS, R. V. Utilizando a programação multicritério (analytic hierarchy process - ahp) para selecionar e priorizar projetos na gestão de portfólio. 2010. Disponível em: http://www.leansixsigma.com.br/acervo/2215922.pdf. Acesso em: 17 jul. 2018.

[33] VILLARROEL, L. C. L. Metanálise das compras públicas sustentáveis federais: a relevância do estado brasileiro na consolidação de uma economia verde nacional. Curitiba: Universidade Federal do Paraná, 2014.

[34] WILSON, F. R.; PAN, W.; SCHUMSKY, D. A Recalculation of the Critical Values for Lawshe's Content Validity Ratio. Measurement and Evaluation in Counseling and Development, v. 45, n. 3, p. 197-210, 2012. 
